\title{
O ensino-aprendizagem do gênero resenha crítica na universidade
}

\author{
Maria Christina da Silva Firmino Cervera (CERVERA, Maria Christina da S. F.) \\ Mestre em Lingüística Aplicada pela Pontifícia Universidade Católica de São Paulo - \\ PUC-SP \\ Professora da Graduação na Universidade Nove de Julho - UNINOVE \\ chriscer@terra.com.br \\ Marina Buzzo (BUZZO, Marina) \\ Doutora na Pontifícia Universidade Católica de São Paulo - PUC-SP \\ marina.buzzo@gmail.com
}

\section{Resumo}

Com aportes em didática de línguas de cunho interacionista sociodiscursivo, em que o gênero é considerado instrumento, Dolz e Schneuwly (1998), o objetivo deste artigo é apresentar a análise de uma resenha crítica inicial e final realizada por um aluno universitário, no que se refere às capacidades de linguagem, a partir de uma seqüência didática do gênero resenha crítica elaborada e inspirada em Machado, Lousada e Abreu-Tardelli (2004) e aplicada a universitários. Os resultados mostram que trabalhar a produção de resenhas críticas acadêmicas, com uma seqüência didática, pode ser um meio de reflexão e apropriação do gênero pelos alunos.

Palavras-chave: ensino-aprendizagem, interacionismo sociodiscursivo, gênero, sequência didática, resenha crítica.

\begin{abstract}
Based on language teaching from a socio discursive interactionist perspective, where genre is considered an instrument, according to Dolz and Schneuwly (1998), the objective of this article is to present and analyze language usage in initial and final critical reviews written by a college student. A critical review genre didactic sequence, based on Machado, Lousada and Abreu-Tardelli (2004), was administered to the student. The results show that following a didactic sequence in teaching-learning how to write academic critical reviews offers students the opportunity to reflect upon and become proficient in this genre.
\end{abstract}

Keywords: teaching-learning, socio-discursive interactionism, genre, didactic sequence, critical review. 


\section{Introdução}

No final da década de 90, em decorrência do processo de privatização do ensino superior levado a cabo pelo governo e da exigência do mercado de trabalho em requerer mão-de-obra especializada, houve um grande aumento de instituições particulares. Esse movimento de expansão e de maior acesso ao ensino superior contribuiu para a entrada na universidade de alunos provenientes do ensino médio, em especial do público que ainda apresenta problemas no uso da linguagem, principalmente da linguagem escrita mais formal, conforme atestam as inúmeras avaliações realizadas nos últimos anos.

Os problemas apresentados pelos alunos de primeiro ano do ensino superior particular noturno decorrem de inúmeros fatores, que vão desde a sobrecarga de trabalho que têm durante o dia, o que dificulta uma dedicação maior ao curso, até a formação na educação básica pública, que faz com que os alunos cheguem à universidade com defasagens de aprendizagem de ordens diversas.

Assim, é necessário considerar que profissionais de diferentes áreas defrontamse com sérios problemas em seu trabalho, quando se deparam com a exigência de terem capacidades de leitura e de produção de textos bem desenvolvidos (MACHADO; LOUSADA; ABREU-TARDELLI, 2004, p. 13) - problema que é correntemente posto por meus alunos.

Nesse sentido, um dos grandes entraves para a produção escrita é a falta de familiaridade com o saber dizer e o saber fazer do meio acadêmico, isto é, com as práticas de linguagem que o constituem. Os gêneros apresentam características complexas e, para sua produção, é preciso que sejam desenvolvidas múltiplas capacidades que vão além da mera organização ou uso das formas gramaticais do português padrão.

Ao apontar para a preocupação com o ensino de gêneros na academia, um dos efeitos observados é a emergência de pesquisas sobre esse tipo de ensino e a necessidade de elaboração de novos materiais didáticos mais adequados a essa demanda. Vale ressaltar que, no Programa de Estudos Pós-Graduados em Linguística Aplicada e Estudos da Linguagem, da Pontifícia Universidade Católica de São Paulo (LAEL-PUC/SP), já se desenvolveram inúmeras pesquisas sobre gêneros e elaboração de novos materiais didáticos destinados ao seu ensino e aprendizagem. Para os pesquisadores que atuam ou atuaram nessa linha, o ensino-aprendizagem de leitura e de produção de textos, bem como os materiais didáticos usados nesse âmbito, devem centrar-se no estudo de gêneros textuais, considerando as diferentes formas de sua realização linguístico-discursiva, e para isso são relevantes pesquisas que se voltem para a concepção e avaliação de instrumentos capazes de mobilizar e possibilitar o desenvolvimento das capacidades de linguagem. Segundo Machado e Cristóvão (2007), inúmeros pesquisadores que têm mostrado a importância de serem ensinados diferentes gêneros na escola e na universidade, propondo, como resultado de suas pesquisas, materiais didáticos adequados, a exemplo das pesquisas desenvolvidas pelo Grupo ALTER $^{1}$ (Análise de Linguagem, Trabalho Educacional e suas Relações) de pesquisa do CNPq. Esse grupo é coordenado pela Prof ${ }^{a} \operatorname{Dr}^{a}$ Anna Rachel Machado e Prof $^{a} \operatorname{Dr}^{a}$ Ana Maria de Mattos Guimarães e reúne pesquisadores de sete universidades brasileiras, uma portuguesa e uma Argentina, doutorandos, mestrandos e bolsistas de IC, tendo como objetivo colaborar para o desenvolvimento de um quadro teórico-

\footnotetext{
${ }^{1} \mathrm{O}$ registro do Grupo Alter no CNPD encontra-se disponível em:

<http://dgp.cnpq.br/buscaoperacional/detalhegrupo.jsp?grupo=0071801UNZ1IKM>. Acesso em: 17 out. 2007.
} 
metodológico, no âmbito da teoria do interacionismo sociodiscursivo (BRONCKART, 2003b, ss), capaz de levar a compreender as relações entre linguagem e trabalho e, mais especificamente, entre linguagem e trabalho educacional.

Dessas pesquisas, vêm resultando materiais didáticos denominados sequências didáticas de gêneros e reflexões teóricas que podem subsidiar a sua elaboração. As bases teóricas desses materiais encontram-se nos trabalhos desenvolvidos pela equipe da Didática de Línguas da Faculdade de Educação e Psicologia da Universidade de Genebra, principalmente em Dolz e Schneuwly (1998) e Pasquier e Dolz (1996), com aportes teórico-metodológicos de Bronckart (2003a, 2003b, 2004, 2006, dentre outros). De acordo com esse grupo, "uma sequência didática é um conjunto de atividades escolares organizadas, de maneira sistemática, em torno de um gênero textual oral ou escrito” (DOLZ; NOVERRAZ; SCHNEUWLY, 2004, p. 97).

\section{Pressupostos teóricos}

O interacionismo sociodiscursivo (doravante ISD), corrente da psicologia de linguagem, que tem como base pressupostos vygostkyanos, propõe ser considerado como um elemento para a construção da ciência do humano, uma ciência que não compartimentaliza os saberes, sem ser especificamente só psicológica ou só sociológica ou lingüística. Em relação a essa última, o ISD, ao retomar criticamente teorias lingüísticas, privilegia as que reconhecem a primazia da dimensão social da linguagem, especialmente a teoria bakhtiniana sobre gêneros.

\section{Didática de línguas}

Desde o início da década de 1980, a equipe de Didática de Línguas da Faculdade de Psicologia e Ciências da Educação da Universidade de Genebra vem se dedicando a investigar temas relacionados à didática do francês como língua materna. Como maiores expoentes dessa equipe hoje em dia, ${ }^{2}$ figuram o próprio Bronckart, Schneuwly e Dolz. Bernard Schneuwly, professor dessa faculdade, atualmente se dedica a elaborar princípios e métodos em didática do francês. Joaquim Dolz, mestre de ensino e de pesquisa na mesma instituição, volta-se para estudar o ensino-aprendizagem da produção de gêneros textuais orais e escritos. Assim, apresentaremos, na próxima seção, alguns dos aspectos definidos por esses autores como essenciais para o trabalho efetivo em sala de aula, tais como o papel do ensino no desenvolvimento, o gênero como foco do ensino, a distinção entre texto e gênero, e o gênero como instrumento.

\section{Qual é o papel do ensino no desenvolvimento?}

Quanto ao papel do ensino no desenvolvimento humano, para Dolz, Noverraz e Schneuwly (2004), a atividade de ensinar deve se pautar em critérios de tomada de decisões que levem em conta a validade didática para cada turma e para a situação discursiva, considerando-se "as possibilidades efetivas de gestão do ensino, a coerência dos conteúdos ensinados, assim como os ganhos de aprendizagem” (DOLZ; NOVERRAZ; SCHNEUWLY, 2004, p. 67).

\footnotetext{
${ }^{2}$ É importante registrar que a Escola de Didática, uma linha teórica francófona sobre a didática de disciplinas escolares, cujos nomes fundadores são Chevelard, Brousseau, Develay e Halté, representa uma das origens teóricas dessa equipe, que atualmente se ligam diretamente ao ISD.
} 
Para essa tomada de decisões ser produtiva, é preciso que se tenham muito claros os objetivos que se quer atingir. Na visão desses autores, inspirando-se em uma concepção interacionista, deve-se priorizar o funcionamento comunicativo dos alunos, ou seja:

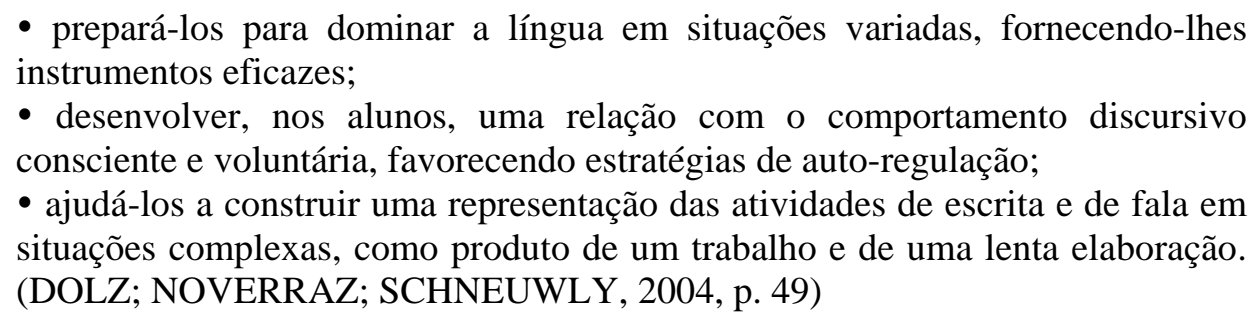

\section{Os gêneros como instrumentos e o modelo de produção de textos}

A atividade humana é concebida como tripolar, pois envolve ao mesmo tempo um sujeito (primeiro pólo), que age sobre objetos ou situações (segundo pólo), utilizando objetos específicos, socialmente elaborados (terceiro pólo), chamados de instrumentos, conforme resgata Schneuwly (1994/2004, p. 23) d'A ideologia alemã (MARX; ENGELS, 1845/2002).

Reportando-se à noção de gênero discursivo, conforme definido por Bakhtin (2003), Schneuwly (2004) defende a tese de que "gênero de texto é um instrumento", no sentido de que pode constituir um fator de desenvolvimento das capacidades de linguagem - as de ação, as discursivas, as lingüístico-discursivas -, considerando-se que ele medeia a atividade de ensino-aprendizagem de produção de textos. Afinal, "os instrumentos encontram-se entre o indivíduo que age e o objeto sobre o qual ou a situação na qual ele age” (SCHNEUWLY, 2004, p. 23).

No que se refere à definição do conteúdo ou referente textual, deve-se levar em conta um conjunto de conhecimentos do mundo físico e do social que são explicitamente evocados e que são provenientes do conjunto de conhecimentos estocados e organizados na memória do produtor do texto.

\section{Os problemas da transposição didática e as seqüências didáticas}

Em relação aos procedimentos de transposição didática, Bronckart, citado por Machado (2001), assinala que a análise da atividade educacional deve constituir-se como um passo inicial, incidindo sobre os três níveis constitutivos dessa atividade: o do sistema educacional (conjunto de instruções oficiais e de textos que expressam as expectativas da sociedade); o dos sistemas de ensino (instituições escolares que se diferenciam em função da idade, nível cognitivo suposto e estatuto sócio-econômico dos alunos); e o dos sistemas didáticos (estruturas particulares constituídas pelo professor, pelos alunos, pelos objetos de conhecimento e pelas relações entre esses três elementos). O ponto mais específico do processo de transposição didática para o ensino de produção de textos, tal como visto pelos pesquisadores de Genebra da Didática de Línguas, é a construção da seqüência didática (doravante SD). A noção de SD utilizada para esta pesquisa repousa na estabelecida por Dolz e Schneuwly (1998), e Dolz, Noverraz e Schneuwly (2004).

\footnotetext{
${ }^{3}$ Não vamos nos aprofundar, entretanto, na noção de gênero (discursivo) em Bakhtin, por termos assumido, neste trabalho, a noção de gênero de texto para o ISD (conforme já justificado).
} 
Para Schneuwly (2004, p. 97), "sequência didática é um conjunto de atividades escolares organizadas, de maneira sistemática, em torno de um gênero textual oral ou escrito". A SD tem a finalidade de ajudar os alunos a dominar melhor um gênero de texto, o que vai lhes permitir escrever ou falar de maneira adequada em uma situação de comunicação. A estrutura dessa SD é constituída por três etapas inter-relacionadas: na primeira, há produção de textos pelos alunos com o objetivo de serem avaliadas as capacidades iniciais e identificados os problemas; na segunda, são desenvolvidos módulos, nos quais os alunos desenvolvem atividades direcionadas para a apropriação das características fundamentais do gênero estudado; na terceira, há uma produção final, na qual os alunos avaliam e revisam suas produções iniciais, guiados por uma ficha de controle, construída individual ou coletivamente durante os módulos.

Para a elaboração de uma seqüência didática, que se julgue eficiente no processo de ensino-aprendizagem, há necessidade de se construir um modelo didático do gênero que se queira ensinar, conforme já o dissemos. O modelo didático de gênero guia ações do professor-pesquisador e evidencia o que pode ser "ensinável” por meio da seqüência didática. O modelo é descritivo e apreende o fenômeno complexo que é a aprendizagem de um gênero, no nosso caso, resenha crítica acadêmica.

\section{Modelo didático de gênero}

O ensino de leitura e produção de gênero de textos em língua materna e língua estrangeira, centrado na noção de gêneros, tem sido bastante difundido no meio científico e educacional. A construção de um modelo didático de gênero permitiria a visualização das dimensões constitutivas do gênero e a seleção das que podem ser ensinadas e das que são necessárias para um determinado nível de ensino. Dolz e Schneuwly (1998) afirmam que o modelo didático precisa apresentar duas características essenciais: a de constituir-se numa síntese prática que se destina a orientar as intervenções docentes e a de esclarecer as dimensões ensináveis desenvolvidas nas seqüências didáticas. Dessa forma, o modelo didático facilita o conhecimento adequado do funcionamento dos gêneros.

Nesse sentido, o modelo didático do gênero de texto, a ser apropriado, é o resultado da descrição provisória das principais características de um gênero, voltadas ao ensino, ou seja, das características ensináveis numa dada situação didáticopedagógica, não significando que seja um modelo perfeito do ponto de vista teórico, mas sim eficiente para os objetivos didáticos a serem alcançados.

Bronckart (2003a), por sua vez, aponta para um problema que ocorre nos procedimentos metodológicos na utilização de um gênero em sala de aula. $\mathrm{O}$ autor destaca a diversidade ilimitada e a variabilidade concreta dos gêneros, o que acarreta problemas metodológicos centrais na classificação e identificação das características de um gênero. Esse autor acredita que uma forma para uma possível classificação seria identificar os gêneros existentes na interação social e selecionar um corpus pertinente e, a partir das particularidades encontradas (pré-concebidas socialmente), poder-se-ia chegar a um primeiro critério para a identificação de um gênero: as características mais comuns aceitas pela sociedade para sua definição. As características encontradas, fossem semelhantes ou diferentes, viriam a favorecer a construção do modelo didático que implicaria as três capacidades correspondentes aos três níveis do folhado textual do modelo de produção de Bronckart, que são as capacidades de ação, as capacidades discursivas e as capacidades lingüístico-discursivas.

Finalmente, é necessário salientarmos que construir um modelo didático de um determinado gênero não significa assumir uma posição determinista e mecânica, 
considerando um determinado conjunto de características como um padrão rígido e inflexível a ser seguido pelos agentes produtores; trata-se, antes, de buscar um modelo provisório, com o objetivo de guiar as atividades didáticas com a finalidade de desenvolver capacidades dos alunos para a produção desse gênero.

\section{Características gerais do gênero resenha crítica acadêmica e modelo didático correspondente}

Em termos de constituição da situação de produção, Machado afirma que as representações do produtor de uma resenha crítica acadêmica são:

X no papel social de especialista em uma determinada área do conhecimento, realiza uma ação de linguagem, na modalidade escrita, que vai materializar-se em um texto a ser publicado em uma revista especializada de sua área, que circula na instituição acadêmica. $\mathrm{X}$ dirige-se a receptores ausentes, também no papel social de especialistas da mesma área, com dois objetivos: em primeiro lugar, o de fazê-los conhecer os aspectos fundamentais de uma obra recémlançada por outro especialista e, em segundo, o de convencer esses destinatários sobre a validade de seu posicionamento (na maioria das vezes positivo) em relação à referida obra. (MACHADO, 2005, p. 253)

A atividade de leitura pressuposta para a produção de uma resenha crítica acadêmica implica, portanto, a interpretação e a sumarização dos conteúdos. Nesse processo, há mobilização de conteúdos de outras obras pelo resenhista, o que lhe dá condições de estabelecer comparações e de efetuar avaliações. Ele deve considerar ainda que pode estar posicionando-se em relação a uma questão controversa, pois outros leitores podem ter opinião contrária à sua. Nesse caso, faz-se importante apresentar argumentos que validem seu posicionamento, procedimento muito próprio da esfera acadêmica.

Conforme Bronckart (2003b), como já vimos, a infraestrutura do texto é constituída pelo plano global, tipos de discursos e tipos de seqüências textuais.

\section{Metodologia}

\section{A sequência didática de resenha crítica acadêmica aplicada}

A sequência didática aplicada foi adaptada da sequência didática proposta por Machado (2004), para o trabalho com resenhas críticas, de maneira que pudesse aplicála em nosso contexto. Priorizamos alguns dos aspectos do gênero resenha crítica levantados por Machado, Lousada e Abreu-Tardelli (2004a) em nossa seqüência, uma vez que não disporia de tempo suficiente para tratar de todos: plano global mínimo, inserção de vozes por verbos de dizer e adjetivos avaliativos, que se mostravam problemáticos para os alunos em textos já desenvolvidos por eles em aulas precedentes.

O artigo de opinião Sempre leia o original, de Stephen Kanitz, publicado na revista Veja de 14 de maio de 2003, foi selecionado para dar início a essa seqüência didática. Vale ressaltarmos que esse gênero circula muito no contexto universitário e busca, sobretudo, convencer o leitor sobre o tema abordado.

A seqüência didática proposta desenvolveu-se em 14 aulas (de 90 minutos cada), das quais as duas primeiras foram dedicadas à apresentação, para os alunos, das linhas 
gerais do trabalho que seria desenvolvido com eles sobre o gênero resenha crítica acadêmica.

A Tabela 1 a seguir apresenta a seqüência adaptada e aplicada.

\begin{tabular}{|c|c|c|}
\hline Modulo & Objetivos & Duração \\
\hline Apresentação & $\begin{array}{l}\text { - Entender, a partir da explicação do professor, em linhas } \\
\text { gerais, o trabalho a ser realizado com o gênero resenha } \\
\text { crítica acadêmica, seu objetivo e uso. }\end{array}$ & $\begin{array}{l}2 \text { aulas } \\
\text { (90 } \\
\text { minutos) }\end{array}$ \\
\hline $\begin{array}{l}\text { Oficina } 1 \\
\text { Levantamento de } \\
\text { dados sobre o } \\
\text { gênero em estudo }\end{array}$ & $\begin{array}{l}\text { - Conhecer a definição de resenha no dicionário. } \\
\text { - Verificar se essa definição é suficiente para se entender } \\
\text { o que é uma resenha. } \\
\text { - Ler o artigo de opinião Sempre leia o original, de } \\
\text { Stephen Kanitz, publicado na revista Veja de } 14 \text { de } \\
\text { maio de } 2003 \text {. } \\
\text { - Produzir uma resenha crítica temática inicial sobre um } \\
\text { texto dado. }\end{array}$ & $\begin{array}{l}2 \text { aulas } \\
\text { (90 } \\
\text { minutos) }\end{array}$ \\
\hline $\begin{array}{l}\text { Oficina } 2 \\
\text { Diferenciando o } \\
\text { resumo da } \\
\text { resenha }\end{array}$ & $\begin{array}{l}\text { - Conhecer a definição de resumo no dicionário e } \\
\text { compará-la à definição de resenha já apresentada, para } \\
\text { diferenciar uma da outra. } \\
\text { - Ler e comparar textos que são resumos e outros que são } \\
\text { resenhas. } \\
\text { - Verificar o uso de adjetivos avaliativos em resenhas. } \\
\text { - Distinguir um bom resumo de um mau resumo. } \\
\text { - Distinguir uma boa resenha de uma resenha que } \\
\text { apresente problemas, principalmente quanto ao } \\
\text { posicionamento do resenhista. }\end{array}$ & $\begin{array}{l}2 \text { aulas } \\
\text { (90 } \\
\text { minutos) }\end{array}$ \\
\hline $\begin{array}{c}\text { Oficina } 3 \\
\text { Resenhas em } \\
\text { diferentes } \\
\text { situações de } \\
\text { produção } \\
\text { O plano global de } \\
\text { uma resenha }\end{array}$ & $\begin{array}{l}\text { - Conhecer e identificar os vários tipos de resenha na } \\
\text { mídia impressa: resenha de livros, de filmes, de CDs. } \\
\text { - Identificar o plano global de uma resenha. }\end{array}$ & $\begin{array}{l}2 \text { aulas } \\
\text { (90 } \\
\text { minutos) }\end{array}$ \\
\hline $\begin{array}{l}\text { Oficina } 4 \\
\text { A expressão da } \\
\text { subjetividade do } \\
\text { autor }\end{array}$ & $\begin{array}{l}\text { - Identificar e reconhecer os adjetivos avaliativos do } \\
\text { autor em relação à avaliação da resenha. }\end{array}$ & $\begin{array}{l}2 \text { aulas } \\
\text { (90 } \\
\text { minutos) }\end{array}$ \\
\hline $\begin{array}{c}\text { Oficina } 5 \\
\text { Procedimentos de } \\
\text { inserção de vozes } \\
\text { Marcas } \\
\text { lingüísticas do } \\
\text { distanciamento } \\
\text { entre autor e } \\
\text { resenhista }\end{array}$ & $\begin{array}{l}\text { - Entender o uso dos verbos de dizer das ações do autor } \\
\text { do texto a ser resenhado. } \\
\text { - Entender os recursos lingüísticos de distanciamento: } \\
\text { "para o autor”, “segundo o autor”, etc. }\end{array}$ & $\begin{array}{l}2 \text { aulas } \\
\text { (90 } \\
\text { minutos) }\end{array}$ \\
\hline
\end{tabular}




\begin{tabular}{|c|c|c|}
\hline $\begin{array}{c}\text { Oficina 6 } \\
\begin{array}{c}\text { Elaboração de } \\
\text { uma nova } \\
\text { resenha do texto } \\
\text { inicial }\end{array}\end{array}$ & $\begin{array}{c}\text { Elaborar uma nova resenha do texto inicial, observando } \\
\text { o que foi estudado ao longo da SD. }\end{array}$ & $\begin{array}{c}2 \text { aulas } \\
(90 \\
\text { minutos })\end{array}$ \\
\hline
\end{tabular}

Tabela 1: Seqüência didática de resenha crítica acadêmica adaptada e aplicada.

\section{Resultados}

O ponto de partida da sequência aplicada é o artigo de opinião Sempre leia o original, de Stephen Kanitz. Reproduzimos, na Tabela 2 abaixo, o plano global do artigo de opinião trabalhado, como objeto da resenha crítica:

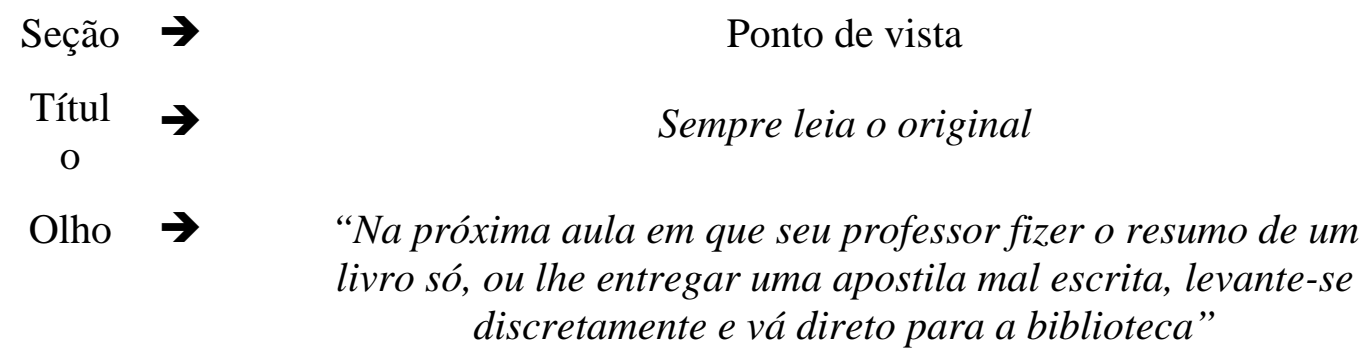
$\$ 1 \rightarrow$ como antigamente. Muitos descobriram que alguns professores nem fazem tanta falta assim. Descobriram também que nas bibliotecas estão os livros originais, as obras que seus professores usavam para dar as aulas, os grandes clássicos, os autores que fizeram suas ciências famosas.

Plano global

Uma greve geral dos professores alguns anos atrás teve uma conseqüência interessante. Reintroduziu, para milhares de estudantes, o valor esquecido das bibliotecas. Os melhores alunos readquiriram uma competência essencial para o

\$1 $\rightarrow$ mundo moderno - voltaram a aprender sozinhos, autores que fizeram suas ciências famosas.

Muitos professores se limitam a elaborar resumos malfeitos dos grandes livros. Quantas vezes você

§2 $\rightarrow$ já assistiu a uma aula em que o professor parecia estar lendo o material? Seria bem mais motivador e eficiente deixar que os próprios alunos lessem

Uma greve de professores

A

conseqüência dessa greve: 0 retorno às bibliotecas

A (re)aquisição de uma capacidade importante hoje em dia: aprender sozinho (autonomia)

A

(re)descoberta dos textos originais

Os resumos malfeitos dos professores

O professor 
os livros. Os professores serviriam para tirar as dúvidas, que fatalmente surgiriam.

Hoje, muitas bibliotecas vivem vazias. Pergunte a seu filho quantos livros ele tomou emprestado da biblioteca neste ano. Alguns nem saberão onde ela fica. Talvez devêssemos pensar em construir mais bibliotecas antes de contratar mais professores. Um professor universitário, ganhando 4.000 reais por mês ao longo de trinta anos (mais os cerca de vinte da aposentadoria), permitiria ao Estado comprar em torno de 130.000 livros, o suficiente para criar 130 bibliotecas. Seiscentos professores poderiam financiar 5.000 bibliotecas de 10.000 livros cada uma, uma por município do país.

Universidades são, por definição, elitistas, para a alegria dos cursinhos. Bibliotecas são democráticas, aceitam todas as classes sociais e etnias. Aceitam curiosos de todas as idades, sete dias por semana, doze meses por ano. Bibliotecas permitem ao aluno depender menos do professor e o ajudam a confiar mais em si.

Nunca esqueço minha primeira visita a uma grande biblioteca, e a sensação de pegar nas mãos seguida o de cálculo de Newton. Na época, eu queria ser físico nuclear. como um

mediador entre alunos e textos originais para dirimição de dúvidas

A situação de ociosidade das bibliotecas atualmente

A probabilidade de avanço, em uma visão de administrador, no

deslocamento do investimento em contratação de mais professores para investimento em expansão de bibliotecas

A contraposição entre $o$ elitismo das universidades e a democracia das bibliotecas

A conseqüência de menor dependência dos alunos em relação aos professores e incremento da autonomia Relato de experiência pessoal do autor com bibliotecas 
Infelizmente, livros nunca entram em greve para alertar sobre o total abandono em que se encontram nem protestam contra a enorme falta de bibliotecas no Brasil. Visitei no ano passado uma escola secundária de Phillips Exeter, numa cidade americana de 30.000 habitantes, no desconhecido Estado de New Hampshire. Os escola, de NOVE andares, com mais de 145.000 obras. A Biblioteca Mário de Andrade, da cidade de São Paulo, tem 350.000. A bibliotecária americana ganhava mais do que alguns dos professores, ao contrário do que ocorre no Brasil, o que demonstra o enorme valor que se dá às bibliotecas nos Estados Unidos.

Não quero parecer injusto com os milhares de professores que incentivam os alunos a ler livros e a freqüentar bibliotecas. Nem quero que sejam substituídos, pois são na realidade facilitadores do aprendizado, motivam e estimulam os alunos a professores do primário e do colegial. Mas estes estão ficando cada vez mais raros, a ponto de se tornarem assunto de filme, como ocorre em Sociedade dos Poetas Mortos, com Robin Williams.

Na próxima aula em que seu professor fizer o resumo de um livro só, ou lhe entregar uma apostila mal escrita, levante-se discretamente e vá direto para a biblioteca. Pegue um livro original de qualquer área, sente-se numa cadeira Você terá um relato apaixonado, aguçado, com os melhores argumentos possíveis, de um brilhante pensador. Você vai ler alguém que tinha de convencer toda a humanidade a mudar uma forma de pensar.

Um autor destemido e corajoso que estava colocando sua reputação, e muitas vezes seu apaixonadamente para convencer uma pessoa bastante especial: você.

A comparação entre as bibliotecas do Brasil e EUA

A comparação entre o ganho dos professores com o dos bibliotecários norteamericanos

O rareamento de professores que incentivam a

$\rightarrow$ leitura e são facilitadores da aprendizagem
A valorização dos textos $\rightarrow$ originais e da figura do autor

Tabela 2: O plano global do artigo de opinião, Sempre leia o original, de Stephen Kanitz, trabalhado como objeto da resenha crítica.

Pode-se perceber, portanto, que, em relação às operações de linguagem mobilizadas pelo autor, a opção pelo gênero artigo de opinião, pelo tipo de discurso que combina a escolha pelo mundo conjunto com implicação e usando seqüências narrativas e argumentativas, pelos procedimentos de textualização que englobam a coesão verbal e nominal, bem como pelos procedimentos de conexão e modalizações. 


\section{Análise da resenha}

A análise foi feita a partir da comparação das Resenhas Iniciais (RI) e das Resenhas Finais (RF) de um mesmo aluno, nomeado como A1, a partir dos três níveis de análise:

* plano global mínimo trabalhado (descrição técnica, resumo e avaliação crítica);

* procedimentos de inserção de vozes (usos de verbos de dizer);

* uso de adjetivos avaliativos.

\section{Aluno 1}

Plano global mínimo trabalhado

A1, em termos de plano global mínimo trabalhado, recupera os mesmos elementos de descrição técnica tanto na RI quanto na RF - título e autor do texto-fonte:

O autor do texto "Leia sempre o original”, Stephen Kanitz nos traz o fato de uma greve de professores que tinham o objetivo inicial, mas que também acarretou a também, uma outra conseqüência.

É interessante ler o texto "Leia sempre o original”, de Stephen Kanitz pois ele faz um apelo a todos nós, para irmos nas bibliotecas, a buscarmos uma leitura mais profunda.

(RF-A1)

Em relação aos resumos das RI, A1 retoma os seguintes tópicos do texto-fonte apresentados na Tabela 3:

O autor do texto "Leia sempre o original" Stephen Kanitz, nos traz o fato de uma greve de professores que tinham o objetivo inicial, mas que também acarretou a também, uma outra conseqüência.

Ele diz que os alunos decidiram estudar sozinhos, pois eles notavam que poderiam aprender muito mais, pois estavam buscando conhecimento na fonte, palavras vindas direto do autor.

E como seria interessante se os alunos fossem atrás de conhecimento e não tivessem a imagem do professor como aquele que faz tudo pronto, e é só ficar esperando. Temos poucas bibliotecas no Brasil e mesmo assim são poucas freqüentadas, não se dá ênfase para o ensino no Brasil, não querem formar
A greve dos profes-

$\rightarrow$ sores

(Re)aquisição de uma capacidade importante hoje em dia: aprender sozinho (autonomia)

O professor como um mediador entre alunos e textos originais para dirimição de dúvidas 
pessoas inteligentes que saibam do seu direito e lute por eles, formam pessoas conformistas e que sempre esperam um dos outros. [Foca novamente a autonomia, agora pelo seu lado negativo - falta de interesse em desenvolvê-la. É uma inferência não autorizada do aluno.]

Como o autor diz: "Infelizmente, livros nunca entram em greve”, mas nós podemos mudar essa realidade, pois, os livros não falam, mas nós sim, e podemos começar a mudar a partir de nós, convidando amigos, colegas, filhos, esposa, etc.

Tabela 3: Resenhas Iniciais do aluno A1 sobre tópicos do texto fonte.

Já na RF, A1 resgata um número maior de tópicos desenvolvidos no texto-fonte da RF, embora não sejam os mesmos em sua totalidade, como podemos perceber na Tabela 4:
A situação de ociosidade das bibliotecas atualmente

A prescrição de que os alunos devem buscar auxílios nos livros e bibliotecas e não no professor

$\rightarrow \quad(\mathrm{Re})$ aquisição de uma capacidade importante hoje em dia: aprender sozinho (autonomia) (RI-A1)

$$
\text { profunda. }
$$

É interessante ler o texto "Leia sempre o original" de Stephen Kanitz, pois ele faz um apelo a todos nós, para irmos nas bibliotecas, a buscarmos uma leitura mais profunda.

Lembra de uma greve de professores, que fez com que os alunos começassem a estudarem sozinhos e o quanto eles viram que aprendiam mais deste modo.

\begin{tabular}{|c|c|}
\hline$\rightarrow$ & $\begin{array}{l}\text { A prescrição de } \\
\text { que os alunos } \\
\text { devem buscar } \\
\text { auxílios nos livros } \\
\text { e bibliotecas e não } \\
\text { no professor }\end{array}$ \\
\hline & $\begin{array}{l}\text { A greve dos } \\
\text { professores }\end{array}$ \\
\hline & $\begin{array}{l}\text { (Re)aquisição de } \\
\text { uma capacidade } \\
\text { importante hoje em } \\
\text { dia: aprender } \\
\text { sozinho } \\
\text { (autonomia) }\end{array}$ \\
\hline & $\begin{array}{l}\text { A comparação } \\
\text { entre as bibliotecas } \\
\text { do Brasil e EUA }\end{array}$ \\
\hline
\end{tabular}

A prescrição de que os alunos auxílios nos livros e bibliotecas e não no professor

A greve dos
professores

(Re)aquisição de uma capacidade importante hoje em dia: aprender sozinho (autonomia)

Ele é muito feliz em comparar Brasil X EUA, pois no Brasil não há incentivo à leitura, não há investimento em construção de bibliotecas enquanto nos EUA, é dada a sua devida importância. 
O rareamento de professores que incentivam a leitura e são facilitadores da aprendizagem

Nos pede para que não aceite resumos mal feitos e sim a buscarmos livros originais e lembrarmos de o quanto foi difícil para o autor se expressar e entender o que ele diz para cada um.

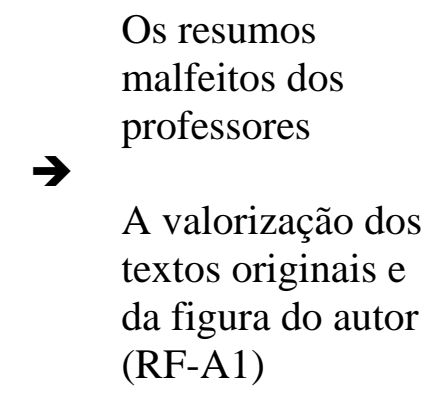

Tabela 4: Resenhas Finais do aluno A1 sobre tópicos do texto fonte.

A1 mantém, da RI, apenas a prescrição de que os alunos devem buscar auxílios nos livros e bibliotecas e não no professor; a greve dos professores; e a (re)aquisição de uma capacidade importante hoje em dia: aprender sozinho (autonomia). Acrescenta quatro tópicos novos em relação à RI (a comparação entre as bibliotecas do Brasil e EUA; o rareamento de professores que incentivam a leitura e são facilitadores da aprendizagem; os resumos malfeitos dos professores; e a valorização dos textos originais e da figura do autor), o que demonstra que o aluno voltou ao texto-fonte antes de elaborar a RF, fazendo dela uma nova leitura. RF:

Observemos, agora, como A1 desenvolve sua avaliação tanto na RI quanto na

Leia sempre um bom livro, entre na história e se deixe levar pois ele foi escrito para você. (RI)

É interessante ler o texto "Leia sempre o original” de Stephen Kanitz, pois ele faz um apelo a todos nós, para irmos nas bibliotecas, a buscarmos uma leitura mais profunda.

Ele é muito feliz em comparar Brasil X EUA, pois no Brasil não há incentivo à leitura, não há investimento em construção de bibliotecas enquanto nos EUA, é dada a sua devida importância. (RF)

A1 optou, na RF, por dar início ao texto com uma avaliação e a colocar outra no decorrer dela. Percebe-se ainda que o segundo texto está mais coeso e traz duas avaliações articuladas às informações (e não num momento final), o que nos mostra que ele conseguiu “deglutir” melhor o texto e assumir uma posição frente a ele. Entretanto, A1 não usou o final da RI, que, sendo uma frase de impacto, de "conselho”, concluiria melhor o texto. 
Em relação ao uso dos verbos de dizer, A1 usa, na RI, os verbos traz e diz:

O autor do texto "Leia sempre o original" Stephen Kanitz, nos traz o fato de uma greve de professores [...]

Como o autor diz: [...]

Ele diz que os alunos decidiram estudar sozinhos [...]

Em RF, A1 usa fazer um apelo, lembrar e pedir:

[...] pois ele faz um apelo a todos nós, para irmos nas bibliotecas, a buscarmos uma leitura mais profunda [...]

Lembra de uma greve de professores [...]

Nos pede para que não aceite resumos mal feitos

(RF-A1)

Tanto na RI quanto na RF, A1 usa verbos que se referem às operações de ação de linguagem, mostrando que busca recuperar, em ambos, o efeito que Kanitz quer atingir.

\section{Adjetivos avaliativos}

A1 não usa adjetivos avaliativos na $\mathrm{R} 1$, no entanto, na $\mathrm{R} 2$, faz uso deles (inclusive articula a um desses adjetivos o intensificador mais):

É interessante ler o texto "Leia sempre o original" de Stephen Kanitz, pois ele faz um apelo a todos nós, para irmos nas bibliotecas, a buscarmos uma leitura mais profunda.

Ele é muito feliz em comparar Brasil X EUA [...]

Isso se deve ao fato de que buscou fazer avaliações na RF, o que não havia realizado na RI. Nesse sentido, os adjetivos foram usados para incluir uma avaliação subjetiva do resenhista, fonte desse julgamento.

\section{Considerações finais}

É importante comentar que o trabalho com uma SD inicia-se a partir da escolha de um determinado gênero a ser ensinado, do que decorre a construção de um modelo didático que reúna as características mínimas observadas em exemplares desse gênero que possam ser comuns numa dada situação e momento específicos. Como assim o fizemos, a proposta de ensino do gênero resenha crítica revelou aspectos importantes no desenvolvimento das capacidades de linguagem.

O esforço de identificar, descrever e classificar gêneros solicitados na academia parece ser útil, uma vez que cada ação de linguagem, trabalhada em seu próprio contexto, propicia o desenvolvimento das capacidades de linguagem requeridas. 
Assim, trabalhar com um modelo didático de gênero orientado por um objetivo educacional, que se volte para minimizar as dificuldades de alunos do primeiro ano de cursos superiores noturnos, pareceu figurar como uma possibilidade produtiva para o ensino-aprendizagem de gêneros acadêmicos.

Além disso, a dinâmica proposta pelas sequências didáticas a serviço do trabalho com modelos didáticos de gêneros não resvala no ensino-aprendizado mecânico, sem reflexão, sem auto-avaliação. Um modelo didático do gênero que se queira ensinar não deve ser tomado mecanicamente; deve ser visto como uma ferramenta que, ao lado de outras, pode vir a ser continuamente adaptada às situações concretas. Deve-se, antes de tudo, compreender a complexidade da ação humana na qual a ação de linguagem se realiza e tomar os textos como espaço em que a dialética, entre a criatividade das ações humanas e as restrições sociais, mostre-se de maneira mais evidente, incluindo aí o quadro das atividades educacionais.

Percebemos, pelos resultados das pesquisas, que os alunos se apropriam do gênero por meio da mediação de estratégias sistemáticas de ensino intervencionista, construindo e reconstruindo a linguagem em várias outras situações concretas de comunicação, ainda mais complicadas, que podem levá-los a uma autonomia progressiva nessas mesmas atividades comunicativas complexas.

Uma proposta para o ensino-aprendizagem do gênero resenha crítica acadêmica ou qualquer outro gênero que se queira ensinar deve levar em consideração, principalmente, a situação de produção, ou seja, dar aos alunos oportunidade de ficcionalizar, tão enfatizada no ensino universitário dos últimos tempos, a partir do que chamamos cases principalmente no curso de Administração Geral: "Imagine que você tem diante de si uma equipe e [...]”. Dessa forma, eles perceberiam, na prática, algo que nós, professores, temos destacado: “Não se esqueça de que você escreve para outro ler". Com o ensino adequado do contexto de produção, pode-se, com um modelo didático apropriado ao gênero que se queira apresentar aos alunos, elaborar as sequências didáticas pertinentes ao desenvolvimento das capacidades de linguagem. Esse movimento pode ocorrer em todas as aulas, qualquer que seja o gênero-objeto de trabalho.

Entendemos que não podemos ensinar um gênero acreditando que existe nele uma estrutura única e estática que venha a formatar todos os outros textos que se entendam pertencentes a esse determinado gênero. É importante salientar que o ensino de qualquer conteúdo deve priorizar uma situação a partir da qual o professor possa levar os alunos à construção ideal do objeto a ser ensinado, desenvolvendo suas representações iniciais sobre o objeto de estudo, o que pode e deve permear todo o processo de ensino-aprendizagem.

Trazendo Bronckart (2006, p. 10) para esta reflexão, na afirmação de que as práticas linguageiras situadas são os instrumentos principais do desenvolvimento humano, no que se refere aos conhecimentos e aos saberes, tanto quanto em relação às capacidades do agir e à identidade das pessoas, os processos de construção social e cultural e os processos de construção da pessoa estão interligados; o desenvolvimento humano é assim percebido na interação com a linguagem.

\section{Referências}

BAKHTIN, Mikhail. (1953). Os gêneros do discurso. In: Estética da criação verbal. Tradução de Paulo Bezerra (nova tradução a partir do russo). 4. ed. São Paulo: Martins Fontes, 2003. 
BRONCKART, Jean-Paul. Gêneros textuais, tipos de discursos e operações psicolingüísticas. Tradução de Rosalvo Pinto. Revista de Estudos da Linguagem v. 11. p. 49-69, 2003a.

(1997). Atividade de linguagem, textos e discursos: por um interacionismo sociodiscursivo. Tradução de Anna Rachel Machado e Péricles Cunha. São Paulo, EDUC, 2003b.

Pourquoi et comment analyser l'agir verbal et non verbal en situation de travail? In: BRONCKART, Jean-Paul; GROUPE LAF. (Eds.). Agir et discours em situation de travail, cahiers de la Section des Sciences de l'Education de l'Université de Genève, 103, Université de Genève, 2004.

Atividade de linguagem, discurso e desenvolvimento humano. Tradução de Anna Rachel Machado e Maria de Lourdes Meirelles Matencio. São Paulo: Mercado de Letras, 2006.

DOLZ, Joaquin; NOVERRAZ, Michele; SCHNEUWLY, Bernard. Seqüências didáticas para o oral e a escrita: apresentação de um procedimento. In: Gêneros orais e escritos na escola. Tradução e Organização de Roxane Helena Rodrigues Rojo e Glaís Sales Cordeiro. Campinas: Mercado de Letras, 2004. p. 95-128.

DOLZ, Joaquin; SCHNEUWLY, Bernard. Pour un enseignement de lóral: initiation aux genres formels à l'école. Paris: ESF Éditeur (Didactique du Français), 1998.

MACHADO, Anna Rachel. Um instrumento de avaliação de material didático com base nas capacidades de linguagem a serem desenvolvidas no aprendizado de produção textual. Intercâmbio v. X. São Paulo: LAEL-PUC/SP, p. 137-147, 2001.

A formação de professores como locus de construção de conhecimentos científicos. In: Maria Cecília Camargo Magalhães. (Org.). A formação do professor como um profissional crítico: linguagem e reflexão. (As faces da Lingüística Aplicada). Campinas: Mercado de Letras, 2004. p. 225-250.

A perspectiva interacionista sociodiscursiva de Bronckart. In: José Luís Meurer; Adair Bonini; Désirée Motta-Roth. (Orgs.). Gêneros: teorias, métodos, debates. São Paulo: Parábola, 2005. p. 237-259.

; CRISTOVÃO, Vera Lúcia Lopes. A construção de modelos didáticos de gêneros: aportes e questionamentos para o ensino de gêneros. Revista Linguagem em (Dis)curso v. 6, n. especial, set./dez, 2006. Disponível em: <http://www3.unisul.br/paginas/ensino/pos/linguagem/0603/09.htm>. Acesso em: 23 jan. 2007.

MACHADO, Anna Rachel; LOUSADA, Eliane; ABREU-TARDELLI, Lílian Santos. S. Resenha. 2. ed. São Paulo: Parábola, 2004.

MARX, Karl; ENGELS, Friedrich. A ideologia alemã. Tradução de Luís Cláudio de Castro e Costa. São Paulo: Martins Fontes, 1845/2002. 
PASQUIER, Auguste; DOLZ, Joaquim. Um decálogo para ensinar a escrever. Cultura y Educación. p. 31-41, 1996.

SCHNEUWLY, Bernard. Gêneros e tipos de discurso: considerações psicológicas e ontogenéticas. In: Gêneros orais e escritos na escola. Tradução e Organização de Roxane Helena Rodrigues Rojo e Glaís Sales Cordeiro. Mercado de Letras, 2004. p. 2139. 